\title{
Effect of PD-I Inhibitor Combined with X-Ray Irradiation on the Inflammatory Microenvironment and Lung Tissue Injury in Mice
}

\author{
Yichao Geng $\mathbb{D}^{1-3, *}$, Shengfa Su ${ }^{2,3, *}$, Li Cao ${ }^{2, *}$, Ting Yang ${ }^{4}$, Weiwei Ouyang ${ }^{2,3}$, Lingfeng Liu ${ }^{2,3}$, \\ Bibo $\mathrm{Wu}^{2,3}$, Qiuning Zhang ${ }^{5}$, Bing $\mathrm{Lu}^{2,3}$, Xiaohu Wang ${ }^{1,5}$ \\ 'The First School of Clinical Medicine, Lanzhou University, Lanzhou, People's Republic of China; ${ }^{2}$ Department of Oncology, The Affiliated Hospital of \\ Guizhou Medical University, Guiyang, People's Republic of China; ${ }^{3}$ Department of Oncology, The Affiliated Cancer Hospital of Guizhou Medical \\ University, Guiyang, People's Republic of China; ${ }^{4}$ Department of Pathophysiology, Guizhou Medical University, Guiyang, People's Republic of China; \\ ${ }^{5}$ Institute of Modern Physics, Chinese Academy of Sciences, Lanzhou, People's Republic of China
}

*These authors contributed equally to this work

Correspondence: Xiaohu Wang, The First School of Clinical Medicine, Lanzhou University, Lanzhou, People's Republic of China, Tel +86 I 390940755 I, Fax +86 931 5196196, Email xhwang@impcas.ac.cn; Bing Lu, Department of Oncology, The Affiliated Hospital of Guizhou Medical University, Guiyang, People's Republic of China, Tel +86I3809432527, Fax +86 85I 65I3076, Email Ibgymaaaa@I63.com

Purpose: This study was designed to evaluate the effects of PD-1 inhibitor on lung tissue morphology and the immune system in a mouse model of radiation-induced lung injury (RILI) and to assess interactions between radiation therapy and PD-1 inhibition.

Methods: Twenty C57BL/6 mice were divided randomly into four groups of five mice each. Mice were treated with an anti-mouse PD-1 monoclonal antibody, whole thorax irradiation, both or neither. Lung tissue morphology and pathological changes were assessed by hematoxylin-eosin staining; lung fibrosis was assessed by Masson staining and analysis of hydroxyproline; CD3+, CD4+, and CD8 $+\mathrm{T}$ lymphocytes in lung tissues were detected immunohistochemically; and the concentrations of transforming growth factor- $\beta 1$ (TGF- $\beta 1$ ) and interleukin-6 (IL-6) in lung tissue were evaluated by cytokine multiplex analysis.

Results: Lung injury scores and indicators of pulmonary fibrosis were higher in mice administration whole thorax irradiation than in control mice. Inflammatory infiltrate scores, alveoli deformation scores, collagen volume fractions and hydroxyproline contents in lung tissues were all significantly higher in mice administered PD-1 inhibitor plus irradiation than in the other three groups. Similarly, the percentages of CD3+ and CD8+T cells and the concentrations of IL- 6 and TGF- $\beta 1$ in lung tissue were significantly higher in mice treated with radiation and PD-1 inhibitor than in the other groups. However, PD-1 inhibitor and irradiation interacted significantly only in the elevation of TGF- $\beta 1$ level.

Conclusion: Whole thorax X-ray irradiation in mice can cause pulmonary injury and fibrosis, which could be exacerbated by PD-1 inhibitors. Radiotherapy combined with PD-1 inhibitors may aggravate RILI by synergistically upregulating TGF- $\beta 1$ expression, thereby affecting the immune-inflammatory microenvironment in the lungs.

Keywords: PD-1 inhibitors, radiotherapy, radiation fibrosis, lung injury, transforming growth factor- $\beta 1$

\section{Introduction}

More than $26 \%$ of malignant tumors are thoracic malignancies, including lung, breast, and esophageal. ${ }^{1}$ Although programmed death 1 (PD-1) inhibitors, which exert anti-tumor effects by activating T lymphocytes, are frequently used to treat thoracic malignancies, PD-1 inhibitors alone are not sufficient to activate the anti-tumor activities of the immune system, having an effective rate of only about $30 \% .^{2-4}$ Radiotherapy is one of the main treatments for malignant thoracic tumors. Radiotherapy may synergize with PD-1 inhibitors to enhance their respective anti-tumor activities, especially in patients with advanced tumors. ${ }^{5}$ 
Radiation-induced lung injury (RILI) is the main dose-limiting toxicity of thoracic radiotherapy. Radiation treatment has been shown to increase the population of infiltrating lymphocytes in lung tissue, resulting in lymphocytic alveolitis, which is closely related to lymphocyte-mediated immune responses. ${ }^{6,7}$ Activation of T lymphocytes by PD-1 inhibitors can mediate immune pneumonitis, with an incidence of about $20 \% .{ }^{8,9}$ Because lung injuries caused by both radiotherapy and PD-1 inhibitors are associated with T-cell-mediated immune-inflammatory responses, the combination of radiotherapy and PD-1 inhibitors may exacerbate lung injury. The ability of PD-1 inhibitors to aggravate RILI has not been consistently reported, either in clinical studies ${ }^{10-13}$ or in animal models. ${ }^{14,15}$ For example, although anti-PD-antibody 1 plus lung radiation did not significantly increase the risk of pneumonitis in CBA mice, ${ }^{14}$ a PD-1 inhibitor combined with radiation led to significant lung injury in orthotopic tumor-bearing C57BL/6 mice. ${ }^{15}$ Because of the difficulty obtain lung tissues from patients to assess the effects of PD-1 inhibitors on RILI, the present study utilized a mouse model to evaluate the effects of PD-1 inhibitor on RILI and to investigate the potential mechanism of action.

\section{Materials and Methods}

\section{Animal Grouping and Treatment}

Care of animals followed the Laboratory Animals-Guidelines for ethical review of animal welfare of China (GB/T 35892-2018), and all animal experiments were approved by the Animal Experimental Ethics Committee of Guizhou Medical University (No. 1901009). Twenty healthy specific pathogen free female C57BL/6 mice, aged 6-8 weeks, weighing $20-25 \mathrm{~g}$ and with normal reflexes, were housed in a clean animal facility (temperature: $23-25^{\circ} \mathrm{C}$, relative humidity: $45-55 \%$ ) and provided free access to food and water.

\section{Main Instruments, Equipment, and Reagents}

The Precise medical linear accelerator was from Elekta, Co. Ltd. (Stockholm, Sweden); the Navios flow cytometer was from Guangzhou Flow Biotechnology Co. Ltd. (Guangzhou, China); and the multifunctional microplate reader was from BioTek Co. Ltd. (Winooski, VT, USA). The anti-mouse PD1 monoclonal antibody (catalogue number BE0146) was from BioXcell Co. Ltd. (West Lebanon, NH, USA); and the anti-mouse CD3 and CD4 polyclonal antibodies and anti-mouse CD8 monoclonal antibody were from Servicebio Biotechnology Co. Ltd. (Wuhan, China). The multifactor detection kit was from BioLegend (San Diego, CA, USA); the hydroxyproline kit was from Jiancheng Bioengineering Institute Co. Ltd. (Nanjing, China); and the HE staining and Masson staining kits were from Servicebio Biotechnology Co. Ltd.

\section{Irradiation and PD-I Inhibitor Treatment}

The 20 mice were randomly divided into four groups of five mice each group. Mice were treated with whole thorax irradiation plus saline (irradiation group), anti-PD-1 antibody plus mock thoracic irradiation (PD-1 inhibitor group), antiPD-1 antibody plus whole thorax irradiation (combined group), or neither treatment (control group). Mice in the irradiation and combined groups were anesthetized by intraperitoneal injection of $6 \%$ chloral hydrate and fixed under a linear accelerator, with a 1-cm thick wax mold on the chest. The thoraxes of these mice underwent a vertical 0-degree single-field irradiation of the chest with $6 \mathrm{MV}$ X-rays, at a dose of $15 \mathrm{~Gy}$. The irradiation field was $2.5 \times 3.5 \mathrm{~cm}$; the source to skin distance was $100 \mathrm{~cm}$, and the dose rate was $600 \mathrm{cGy} / \mathrm{min}$. The irradiation dose was based on previous research assessing pneumonitis and fibrosis in various strains of mice. ${ }^{16,17}$ The mice were allowed to recover spontaneously. Mice in the PD-1 inhibitor and combined groups were intraperitoneally injected with $200 \mu \mathrm{g}$ of anti-PD-1 antibody 1 week and 30 minutes before irradiation, and $100 \mu \mathrm{g}$ of anti-PD-1 antibody 1, 2, and 3 weeks after irradiation. Mice in the irradiation and control groups were intraperitoneally injected with the same volume of saline at the same time points.

\section{Sample Collection and Processing}

One month after irradiation, the mice in each group were sacrificed after anesthetization with $6 \%$ chloral hydrate. Their lungs were removed, and each left lung was divided into two parts: One part was fixed in $10 \%$ formalin solution;

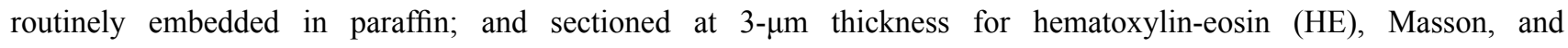


immunohistochemical staining, and the second part was lysed in lysis buffer, homogenized using an ultrasonic homogenizer, and centrifuged. The supernatant of each sample was withdrawn and stored at $-80^{\circ} \mathrm{C}$, along with the remaining lung tissue.

\section{HE Staining}

Paraffin sections were deparaffinized in water and stained with HE as described by the manufacturer. The morphology and pathological changes in the lung tissues were evaluated by light microscopy; five fields per specimen were randomly selected and examined by two pathologists, blinded to the treatment groups. The grade of damage was assessed by evaluating inflammatory infiltrates and alveolar inflammation. ${ }^{18}$ Inflammatory infiltrates were evaluated on a four-point scale, with 0 indicating no or occasional inflammatory cells; 1 indicating a few loosely arranged inflammatory cells; 2 indicating many cells in the intrastitial and intra-alveolar spaces; and 3 indicating numerous inflammatory cells in the perivascular space. (2) The four-point scoring scale of Alveolar deformation also evaluated on a four-point scale, with 0 indicating a normal appearance; and 1,2, and 3 indicating mild thickening (little distortion), moderate thickening (increased distortion), and 3: severe thickening (maximal distortion), respectively.

\section{Masson Staining}

Masson staining was performed according to the manufacturer's instructions. Mouse alveolar epithelial cells were stained red, and collagen fibers were stained blue. Five fields per specimen were randomly selected, and the sections were viewed under an optical microscope. Semi-quantitative analysis was performed using ImageJ software, and the collagen volume fraction (CVF) of each specimen was calculated as the collagen area of the field/total area of the field.

\section{Hydroxyproline Assay}

Hydroxyproline was assayed using a kit purchased from Nanjing Jiancheng Bioengineering Institute Co. Ltd. Mouse lung tissue (30 mg wet weight) was placed in a test tube and cut into pieces. Hydrolysate $(1 \mathrm{~mL})$ was added and the tube was incubated in a water bath for $20 \mathrm{~min}$. The optical density (OD) value was obtained by measuring absorbance at a wavelength of $550 \mathrm{~nm}$, according to the manufacturer's instructions. Hydroxyproline content was calculated using the formula: hydroxyproline content $(\mu \mathrm{g} / \mathrm{mg}$ wet weight $)=[$ (measured OD value - blank OD value $) /($ standard OD value blank OD value $)] \times$ standard content $(5 \mu \mathrm{g} / \mathrm{mL}) \times($ total volume of hydrolysate $10 \mathrm{~mL} / \mathrm{mg}$ tissue wet weight)

\section{Immunohistochemical Staining}

Routine paraffin sections were deparaffinized in water and microwaved for antigen retrieval. The sections were placed in a 3\% hydrogen peroxide solution, incubated at room temperature in the dark for 25 min, and washed with PBS three times for 5 min each. For blocking, each tissue section was covered evenly by dropping 3\% BSA into the enclosure, followed by incubation at room temperature for $30 \mathrm{~min}$. The blocking solution was gently shaken off, and primary antibodies (rabbit anti-mouse CD3, CD4, and CD8 antibodies) were added dropwise followed by incubation overnight at $4^{\circ} \mathrm{C}$. The sections were washed with PBS three times for $5 \mathrm{~min}$ each, followed by incubation with HRP-labeled secondary antibody for $50 \mathrm{~min}$ at room temperature. The sections were again washed with PBS three times for 5 min each. DAB was visualized, dehydrated, made transparent, and mounted in neutral gum. The average optical densities (AOD) of CD3, CD4, and CD8, calculated as integrated optical density/positive expression area, were determined semiquantitatively using ImageJ software.

\section{Cytokine Levels in Lung Tissue}

Cytokine levels in lung tissue were evaluated using LEGENDplex multi-analyte flow assay kits (Biolegend), according to the manufacturer's protocol. Mouse lung tissue was weighed (wet weight: $20 \mathrm{mg}$ ), cut into pieces on ice, homogenized for $3 \mathrm{~min}$, and centrifuged at $1000 \times \mathrm{g}$ for $5 \mathrm{~min}$. A $25 \mu \mathrm{L}$ aliquot of each supernatant was mixed with $25 \mu \mathrm{L}$ of Chemokine Capture Beads and $25 \mu \mathrm{L}$ of assay buffer were added. The samples were shaken, washed, incubated in the dark for $2 \mathrm{~h}$, and centrifuged at $1000 \times g$ for $5 \mathrm{~min}$. The supernatant was discarded, $200 \mu \mathrm{L}$ wash buffer were added, and the tube was shaken and centrifuged at $1000 \times \mathrm{g}$ for $5 \mathrm{~min}$. After discarding the supernatant, $25 \mu \mathrm{L}$ of detecting antibody 
were added; and the tube was shaken and incubated at room temperature in the dark for $1 \mathrm{~h}$. A $25 \mu \mathrm{L}$ aliquot of SAPE was added, and the tube was shaken, incubated at room temperature for $30 \mathrm{~min}$ in the dark, and centrifuged at $1000 \mathrm{~g}$ for $5 \mathrm{~min}$. The supernatant was discarded, and the beads were washed once with $200 \mu \mathrm{L}$ wash buffer and centrifuged at 1000 $g$ for $5 \mathrm{~min}$. After discarding the supernatant, $300 \mu \mathrm{L}$ of $1 \mathrm{x}$ wash buffer were added to each tube, and the samples loaded onto the column. Concentrations of detect TGF- $\beta 1$, IL- 6 , interferon-gamma (IFN- $\gamma$ ), tumor necrosis factor- $\alpha$ (TNF- $\alpha$ ), IL-4 and IL-17A were measured, with the data analyzed using LEGENDplex v8.0 software.

\section{Statistical Analysis}

Results were expressed as mean \pm standard deviation (SD). Interactions between PD-1 inhibitor and irradiation were analyzed by two-way factorial ANOVA, followed by Bonferroni post-hoc tests. All statistical analyses were performed using IBM SPSS Statistics for Windows, Version 23.0, with $\mathrm{P}<0.05$ considered statistically significant. All graphs were created using GraphPad version 8.0.

\section{Results}

\section{Pathological Characteristics of Lung Tissue} HE Staining

Examination of lung tissue samples from control group mice showed that the alveolar walls were slender, tissue structure was clear, and capillary walls were relatively intact, with no significant alveolar wall breakage or hemorrhage. In the PD1 inhibitor group, the lung tissue was mildly congested and edematous, with a few inflammatory cell infiltrates. In the irradiation group, the alveolar septa were thickened, pulmonary interstitial congestion and edema were significant, the alveolar spaces were smaller, the weave structure was disordered, and more inflammatory cell infiltrates were observed. In the combined group, the alveolar septa were diffusely thickened and edematous, alveolar spaces were significantly reduced or even disappeared, normal structure was significantly destroyed, and large numbers of inflammatory cell infiltrates were observed (Figure 1). The combined group had the highest histological scores for both inflammatory infiltrates (Figure 2A) and alveoli deformation (Figure 2B), suggesting that lung injury was most severe in mice treated with both PD-1 inhibitor plus irradiation. Two-way ANOVA revealed that treatment with PD-1 inhibitor (F1,16=24.242, $\mathrm{P}<0.001)$ and irradiation $(\mathrm{F} 1,16=47.515, \mathrm{P}<0.0001)$ significantly affected histological scores, but the interaction between $\mathrm{PD}-1$ inhibitor and irradiation was not significant $(\mathrm{F} 1,16=0.970, \mathrm{P}=0.339)$.

\section{Masson Staining}

Masson staining of control lung tissues showed that their structure was intact, with no significant collagen fiber deposition in the lung interstitium. A small amount of collagen fiber was observed in the PD-1 inhibitor group; with higher amounts of collagen fiber deposition in the lung interstitium of the irradiated than in the PD-1 inhibitor group. Normal lung tissue structure was significantly destroyed in mice treated with both irradiation and PD-1 inhibitor, with significant collagen fiber deposition in the alveolar septum (Figure 3).

Semi-quantitative analysis of lung tissue collagen showed that the CVFs of the control, PD-1 inhibitor, irradiation and combined groups were $4.30 \pm 1.06 \%, 10.70 \pm 2.83 \%, 13.30 \pm 2.50 \%$, and $21.00 \pm 3.23 \%$, respectively. Two-way ANOVA showed that treatment with $\mathrm{PD}-1$ inhibitor $(\mathrm{F} 1,16=41.588, \mathrm{P}<0.0001)$ and irradiation $(\mathrm{F} 1,16=75.745, \mathrm{P}<0.0001)$ significantly increased collagen fiber deposition, whereas there was no significant interaction between PD-1 inhibitor and irradiation $(\mathrm{F} 1,16=0.681 \mathrm{P}=0.421)$. Post-hoc analysis showed that $\mathrm{CVF}$ was significantly higher in the combined treatment group than in the other three groups (Figure 4), indicating that lung fibrosis is more severe in mice treated with PD-1 inhibitor and irradiation than in mice treated with either alone.

\section{Determination of Hydroxyproline Content}

Hydroxyproline content is an important indicator of lung fibrosis. The hydroxyproline contents of the control, PD-1 inhibitor, irradiation and combined groups were found to be $0.116 \pm 0.009,0.150 \pm 0.008,0.173 \pm 0.010$, and $0.191 \pm 0.020$ $\mu \mathrm{g} / \mathrm{mg}$, respectively. Two-way ANOVA showed that treatment with $\mathrm{PD}-1$ inhibitor $(\mathrm{F} 1,16=24.582, \mathrm{P}<0.001)$ and irradiation $(\mathrm{F} 1,16=83.782, \mathrm{P}<0.0001)$ significantly increased hydroxyproline contents, but there was no significant 


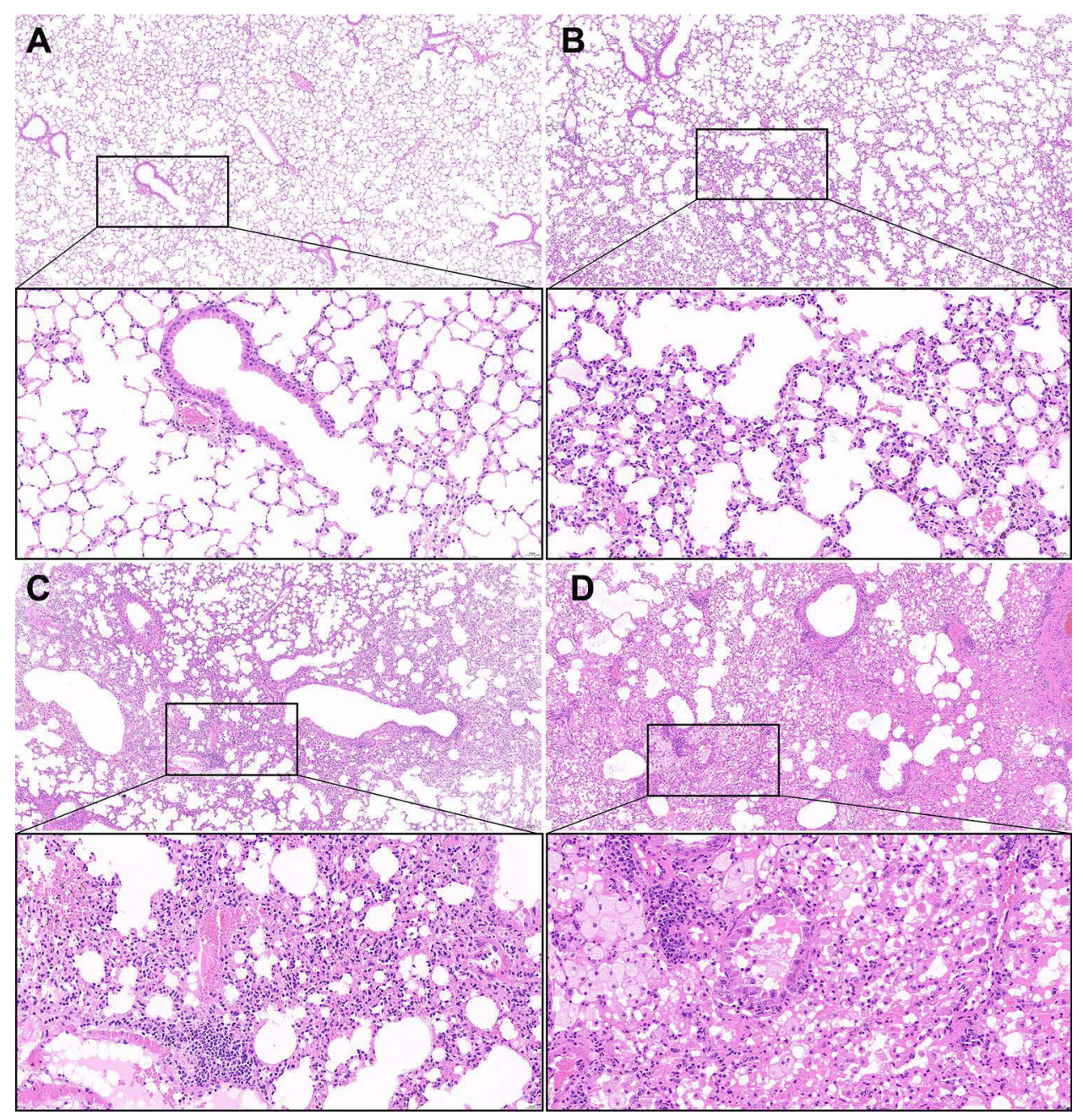

Figure I HE staining of lung tissue I month after irradiation and/or anti-PD-I treatment in each group.

Notes: (A) Control; (B) PD-I inhibitor alone; (C) Irradiation alone; (D) PD-I inhibitor + irradiation.

interaction between PD-1 inhibitor and irradiation (F1,16=2.327, P=0.147). Post-hoc analysis showed that hydroxyproline contents were significantly higher in the combined treatment group than in the other three groups (Figure 5).

\section{Lymphocyte Infiltration into Mouse Lung Tissue}

Immunohistochemical staining showed that $\mathrm{CD} 3+, \mathrm{CD} 4+$, and $\mathrm{CD} 8+\mathrm{T}$ lymphocytes were present in lung tissue samples (Figure 6). CD3+ $\mathrm{T}$ lymphocyte infiltration was greater in mice treated with PD-1 inhibitor plus irradiation than in control mice, with this increase likely due to an increase in the number of CD8+ lymphocytes (Table 1). Infiltration of CD4+ lymphocytes was not affected by PD-1 inhibitor and/or irradiation $(P>0.05)$. Two-way ANOVA showed that treatment with PD-1 inhibitor $(P<0.001)$ and irradiation $(\mathrm{P}<0.001)$ had significant effects on the infiltration of $\mathrm{CD} 3+\mathrm{T}$ and $\mathrm{CD} 8+\mathrm{T}$ lymphocytes, but not CD4 $+\mathrm{T}$ lymphocytes $(P>0.05)$ into lung tissue, There were no significant interactions $(P>0.05)$ between PD-1 inhibitor and irradiation on $\mathrm{CD} 3+, \mathrm{CD} 4+$ and $\mathrm{CD} 8+\mathrm{T}$ lymphocytes.

\section{Cytokine Expression in Lung Tissue IL-6 Expression}

IL-6 concentrations in the lungs of mice in the control, PD-1 inhibitor, irradiation and combined groups were $13.55 \pm 3.45$, $37.85 \pm 9.33,62.24 \pm 14.11$, and $90.77 \pm 8.51 \mathrm{pg} / \mathrm{mL}$, respectively. Two-way ANOVA showed that treatment with PD-1 inhibitor $(\mathrm{F} 1,16=37.692, P<0.0001)$ and irradiation $(\mathrm{F} 1,16=139.479, P<0.0001)$ significantly increased IL-6 expression, 

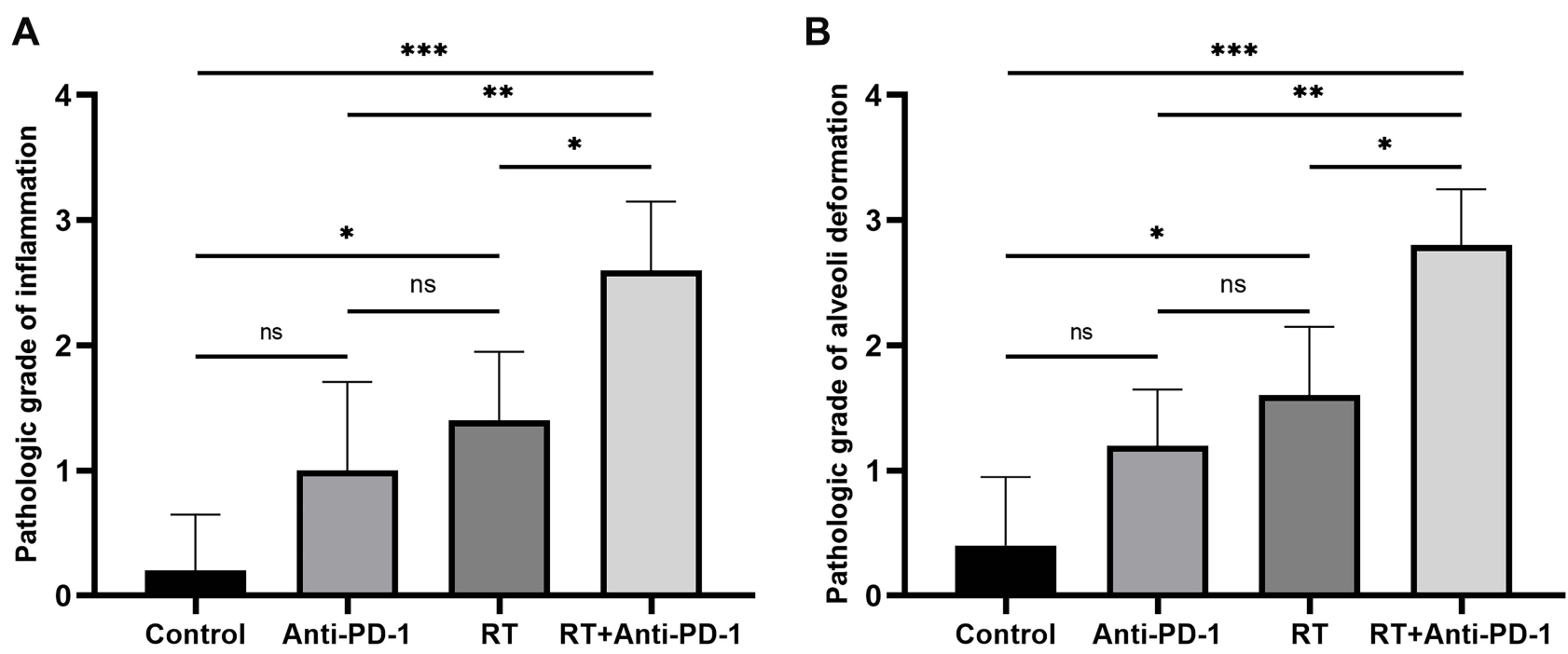

Figure 2 Lung injury scores in the four groups of mice. (A) Inflammatory infiltrate score, (B) Alveoli deformation score. $* \mathrm{P}<0.05, * * \mathrm{P}<0.0 \mathrm{I}, * * * \mathrm{P}<0.00 \mathrm{I}, \mathrm{ns}>0.05$. Abbreviation: RT, radiation therapy.

but there was no significant interaction between PD-1 inhibitor and irradiation (F1,16=0.241, $P=0.630)$. Post-hoc analysis showed that IL-6 levels were significantly higher in the combination group than in the other three groups $(P<0.0001)$.

\section{TGF- $\beta$ I Expression}

TGF- $\beta 1$ concentrations in the lungs of mice in the control, PD-1 inhibitor, irradiation and combined groups were 326.5 $\pm 23.43,1359.77 \pm 464.74,2734.19 \pm 691.73$, and $7966.11 \pm 1074.97 \mathrm{pg} / \mathrm{mL}$, respectively. Two-way ANOVA showed that treatment with PD-1 inhibitor $(\mathrm{F} 1,16=106.55, P<0.0001)$ and irradiation $(\mathrm{F} 1,16=219.534, P<0.0001)$ significantly increased TGF- $\beta 1$ expression and that there was a significant interaction effect between PD-1 inhibitor and irradiation $(\mathrm{F} 1,16=47.630, P<0.0001)$. These results suggest that PD-1 inhibitor and irradiation synergistically increase TGF- $\beta 1$ levels in lung tissue.

The levels of expression of IL-4, IL-17A, TNF- $\alpha$, and IFN- $\gamma$ in each group were below the range of detection, of 4.05 pg $\mathrm{mL}^{-1}, 6.21 \mathrm{pg} \mathrm{mL}^{-1}, 4.35 \mathrm{pg} \mathrm{mL}^{-1}$, and $5.74 \mathrm{pg} \mathrm{mL}^{-1}$, respectively.

\section{Discussion}

The primary characteristic of RILI is lymphocytic alveolitis, which is closely associated with lymphocyte-mediated immune responses. ${ }^{19}$ PD-1 inhibitors can activate T lymphocytes, with the risk of aggravating RILI. There are two clinical manifestations of RILI: early radiation pneumonitis (RP) and late radiation pulmonary fibrosis (RILF), with the latter being irreversible and could eventually lead to respiratory failure. Thus, early treatment with glucocorticoids can result in improvement or recovery in patients with RP, whereas no specific drug has been found to prevent or reverse RILF.

Treatment of mice with PD-1 inhibitor alone resulted in mild lung injury and fibrosis, whereas thorax irradiation with 15 Gy led to severe lung injury and fibrosis. The highest degrees of lung injury and fibrosis observed in the present study were induced by PD-1 inhibitor plus irradiation. Thus, despite PD-1 inhibitor having only mild effects on lung injury and fibrosis, it exacerbated RILI and fibrotic response when combined with irradiation. In clinical practice, the entire lung is usually not irradiated at high doses. Although our experimental model cannot completely reflect the situation of patients with thoracic cancer undergoing radiotherapy, our findings suggest the need to consider the pulmonary toxicity of PD-1 inhibitors when combined with radiotherapy in patients with thoracic malignancies.

We observed no significant interactions between the effects of PD-1 inhibitor and radiotherapy on lung injury scores, CVF, hydroxyproline contents, T lymphocyte infiltration, and IL-6 levels. In contrast, there was a significant interaction between the effects of PD-1 inhibitor and radiotherapy on TGF- $\beta 1$ levels in lung tissue. Taken together, these findings 


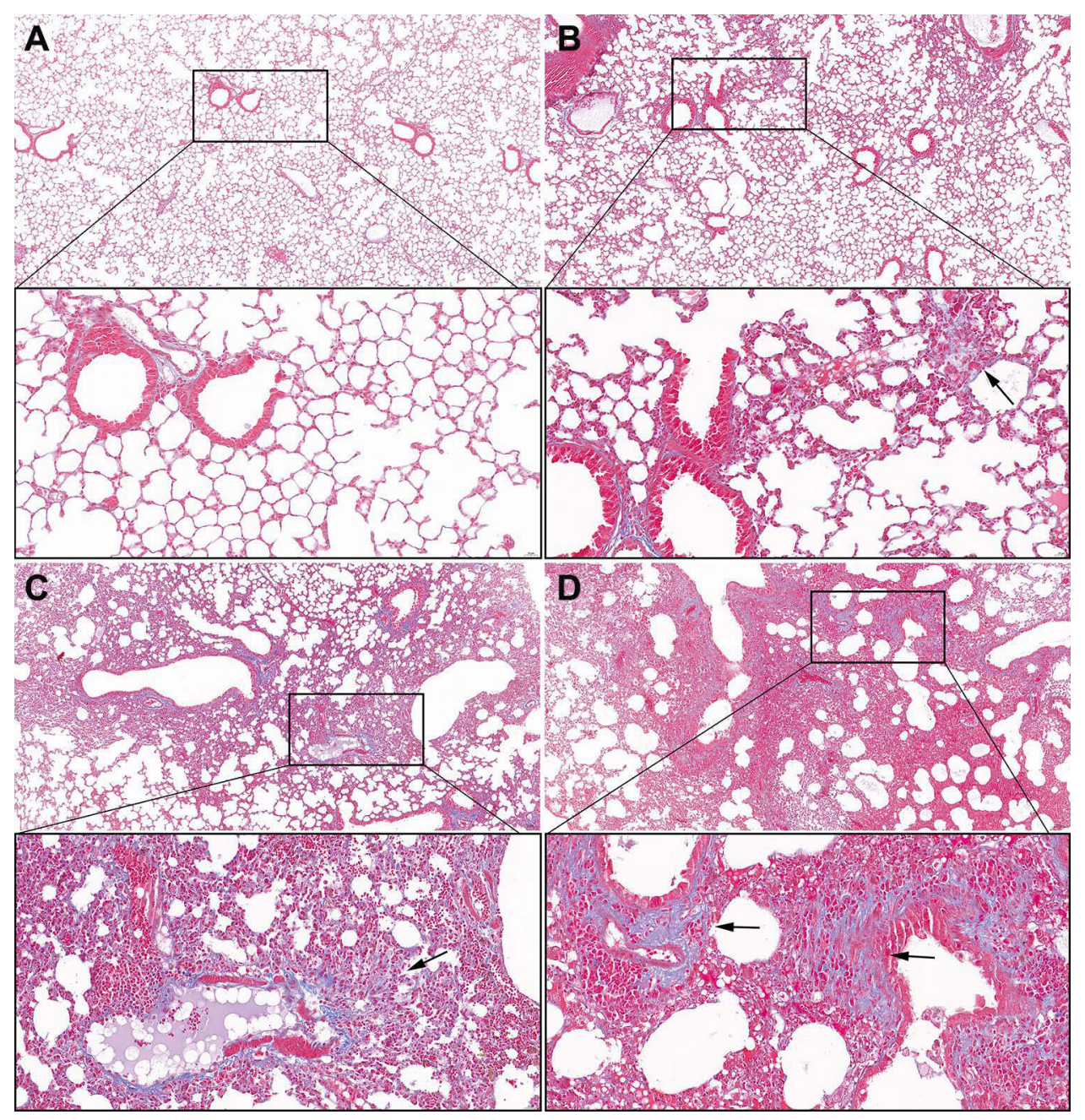

Figure 3 Masson staining of lung tissue I month after irradiation and/or anti-PD-I treatment in each group.

Notes: (A) Control; (B) PD-I inhibitor alone; (C) Irradiation alone; (D) PD-I inhibitor + irradiation. Black Arrow: alveolar fibrosis.

suggest that the combined effects of PD-1 inhibitor and radiotherapy are additive for most parameters but synergistic for others.

The present study found that infiltration of CD8 $+\mathrm{T}$ lymphocytes, rather than CD4+ $\mathrm{T}$ lymphocytes, plays an important role in lung injury induced by the combination of radiotherapy and PD-1 inhibitor. The efficient infiltration into lung tissue by $\mathrm{CD} 8+\mathrm{T}$ cells is important during pathogenesis of lung injury. ${ }^{20}$ Moreover, the infiltration of $\mathrm{CD} 3^{+} \mathrm{T}$ lymphocytes, especially $\mathrm{CD} 8^{+} \mathrm{T}$ cells, was closely associated with myocardial injury induced by radiation combined with PD-1 inhibitor. ${ }^{21}$ This injury was reduced by anti-CD8+ antibodies, but not by anti-CD4+ antibodies, ${ }^{21}$ suggesting that $\mathrm{CD} 8^{+} \mathrm{T}$ lymphocytes play a key role in normal tissue injury induced by radiation combined with PD-1 inhibitors. Despite the ability of $\mathrm{CD}^{+}$or $\mathrm{CD}^{+} \mathrm{T}$ cell inhibition to reduce this damage to normal lung tissue, ${ }^{21}$ the therapeutic effects of both radiotherapy and PD-1 inhibitors on tumors require the infiltration of CD8 $+\mathrm{T}$ cells into the tumor microenvironment, ${ }^{4,22}$ suggesting that blocking $\mathrm{T}$ lymphocytes is likely to reduce these anti-tumor effects. ${ }^{23}$

Identifying the key cytokines associated with lung injury induced by radiation plus PD-1 inhibitors can provide clues to prevent and treat RILI without reducing their anti-tumor effects. IL-6 is a proinflammatory factor that plays an important role in PD-1 inhibitor-associated inflammation, autoimmune inflammation, and radiation-induced injury. Significantly elevated serum IL-6 levels in patients with RP could be used as a marker to predict RILI, ${ }^{24}$ and blocking the IL-6 signaling pathway was shown to inhibit lung fibroblast activation and improve the degree of radiation-induced 


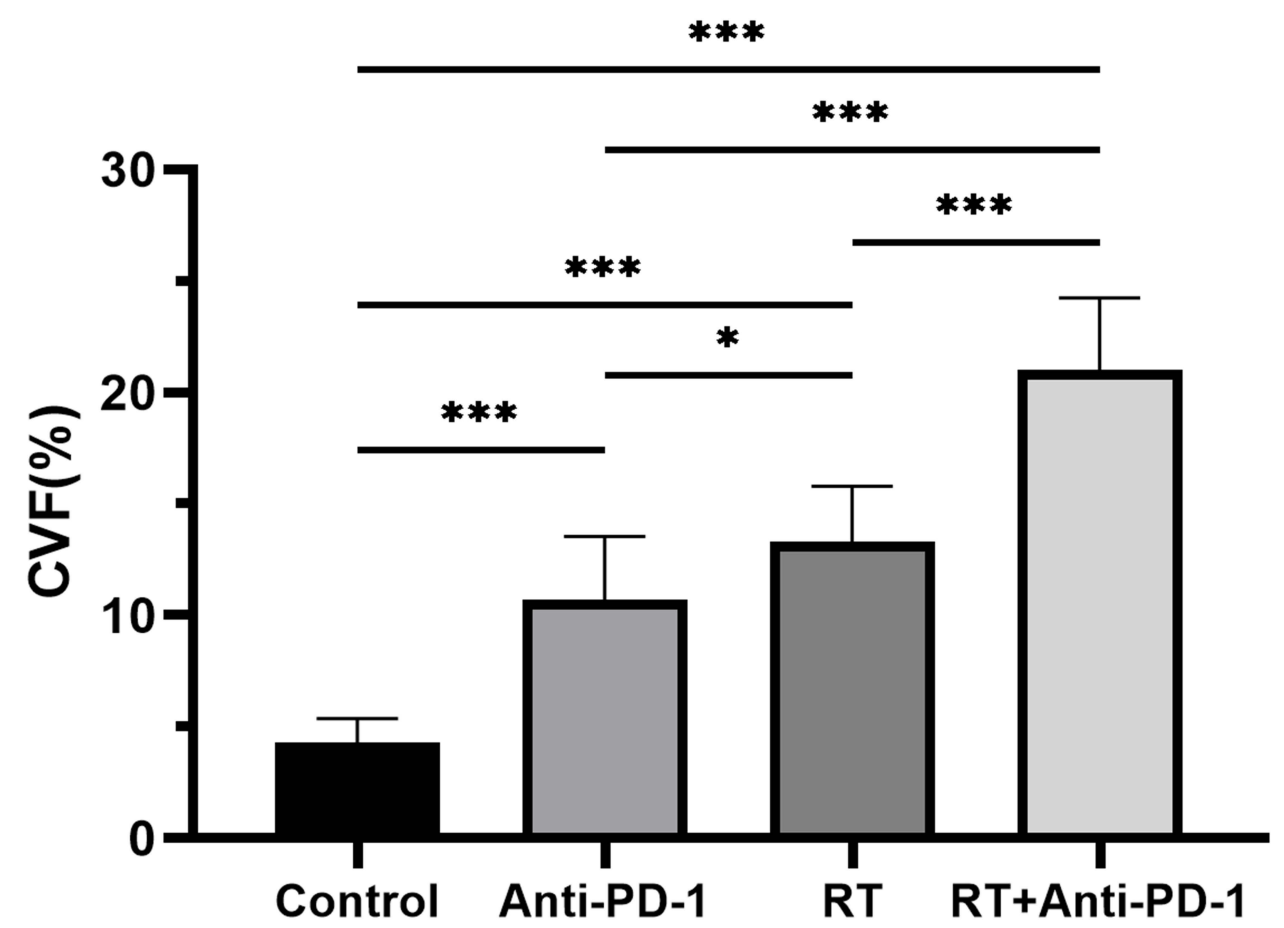

Figure 4 Collagen volume fraction (\%) in lung tissue in the four groups of mice. $* \mathrm{P}<0.05, * * * \mathrm{P}<0.00 \mathrm{I}$. Abbreviation: RT, radiation therapy.

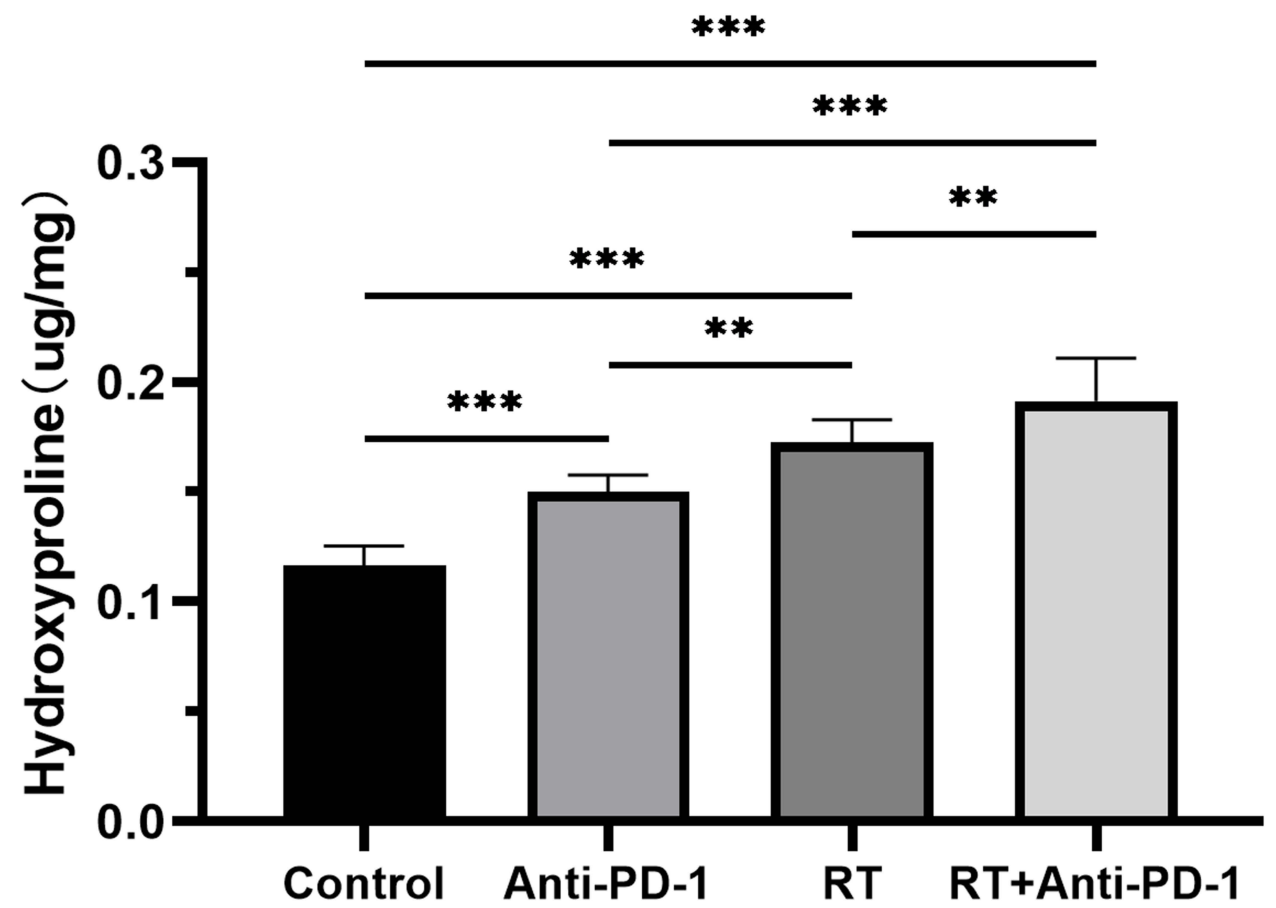

Figure 5 Hydroxyproline content $(\mu \mathrm{g} / \mathrm{mg})$ in lung tissue in the four groups of mice. ${ }^{*} * \mathrm{P}<0.0 \mathrm{I}, * * * \mathrm{P}<0.00 \mathrm{I}$. Abbreviation:RT, radiation therapy.

fibrosis in mice. ${ }^{25}$ IL-6 inhibition can also alleviate the inflammatory syndrome resulting from immunotherapy in patients

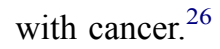

TGF- $\beta 1$ is an important profibrotic factor, which is closely associated with the occurrence and development of radiation-induced pulmonary fibrosis. ${ }^{27}$ TGF- $\beta 1$ expression levels can also be used to predict RILI. ${ }^{28-30}$ Although the 


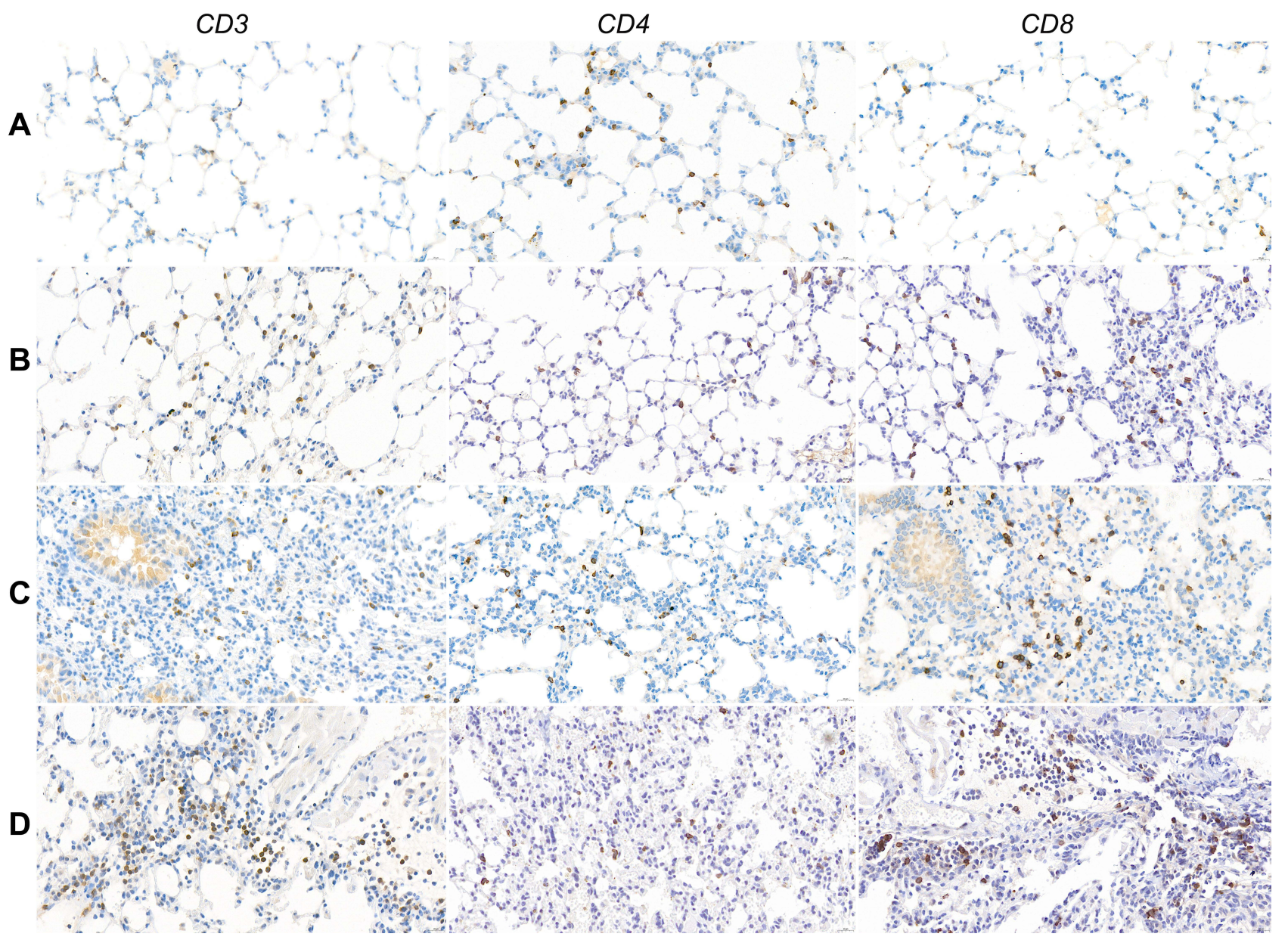

Figure 6 Immunohistochemistry of lymphocyte infiltration in lung tissue I month after irradiation and/or anti-PD-I treatment in each group. (A) Control; (B) PD-I inhibitor alone; (C) irradiation alone; (D) PD-I inhibitor + irradiation.

mechanisms by which radiation induces TGF- $\beta$ activation are incompletely understood, several hypothesis have been suggested. For example, radiation-induced reactive oxygen species (ROS) can activate TGF- $\beta$, with TGF- $\beta$ also inducing ROS production. ${ }^{31}$ Radiation also increases the expression of lactate dehydrogenase-A, which can lead to further activation of TGF- $\beta$ to drive the fibrotic process. ${ }^{32}$ Type II pneumocytes and fibroblasts may play a role in increasing TGF- $\beta$ expression after lung irradiation. ${ }^{33}$ For example, radiation was found to increase the expression of LncRNARP11, which may regulate the process of TGF- $\beta 1$ induced fibrosis. ${ }^{34}$

Blocking TGF- $\beta 1$-mediated signaling pathways may reduce radiation-induced pulmonary fibrosis. The pathological processes of idiopathic pulmonary fibrosis (IPF) and RILF are very similar. ${ }^{35}$ Pirfenidone is an orally active small molecule that has been shown to inhibit the progression of fibrosis in patients with IPF by inhibiting the TGF- $\beta$ pathway. Pirfenidone was found to inhibit the TGF- $\beta$-induced phosphorylation of Smad3, p38, and Akt, key factors in the TGF- $\beta$

Table I Populations of CD3+, CD4+ and CD8+ T-Lymphocytes in Each Group of Mice (\%, Mean \pm SD)

\begin{tabular}{|l|c|c|c|}
\hline Groups & CD3+ & CD4+ & CD8+ \\
\hline Control & $32.20 \pm 3.58$ & $17.70 \pm 2.98$ & $14.40 \pm 2.63$ \\
PD-I inhibitor alone & $40.10 \pm 1.91$ & $17.80 \pm 1.32$ & $21.10 \pm 2.23$ \\
Irradiation alone & $44.20 \pm 3.36$ & $17.70 \pm 1.34$ & $22.50 \pm 2.27$ \\
PD-I inhibitor + irradiation & $48.00 \pm 3.97$ & $15.90 \pm 1.37$ & $28.20 \pm 3.39$ \\
\hline
\end{tabular}


pathway $^{36}$ and to regulate macrophage polarization and reduce radiation-induced pulmonary fibrosis by inhibiting the TGF- $\beta 1 /$ Smad3 pathway. ${ }^{37}$ LY2109761 is a novel selective TGF- $\beta$ inhibitor that inhibits on the phosphorylation of Smad2, attenuating radiation-induced pulmonary fibrosis in mice by inhibiting the TGF- $\beta 1 / \mathrm{Smad} 2$ pathway. ${ }^{38}$ These results suggest that inhibiting TGF- $\beta 1$ attenuates lung injury. ${ }^{36-38}$ Interestingly, TGF- $\beta$ may also be a major obstacle to the optimal activation of anti-tumor $\mathrm{T}$ cell responses by radiation therapy. ${ }^{39}$ Radiation induces TGF- $\beta$ activation, which, in turn, inhibits radiation-induced T cell priming. Thus, TGF- $\beta$ blockade can affect multiple populations of immune cells that contribute to tumor control. ${ }^{40}$

The present study found that the levels of expression of IL- 6 and TGF- $\beta 1$ in lung tissue were increased significantly after radiation combined with a PD-1 inhibitor, with these two treatment methods having a significant interaction effect only on TGF- $\beta$ expression, indicating that TGF- $\beta 1$ plays an important role in lung injury induced by this combination. Blocking TGF- $\beta$ when treated patients with radiation plus PD-1 inhibitors may: enhance their therapeutic efficacy while alleviating RILI.

This study had several limitations. Although this study found that CD8 + T cell infiltration into lung tissue and IL-6 and TGF- $\beta 1$ signaling are involved in the pathogenesis of lung injury and fibrosis in mice treated with a PD-1 inhibitor and irradiation, evaluation of the mechanisms underlying lung injury is inadequate. Further investigations of the mechanisms by which combination therapy increases the expression of IL- 6 and TGF- $\beta 1$ and determination of the effects of inhibiting the IL- 6 and/or TGF- $\beta 1$ signal transduction pathway on lung injury are warranted.

\section{Conclusion}

In summary, although PD-1 inhibitor alone induced mild lung injury, its combination with radiation exacerbated RILI by affecting the immune-inflammatory microenvironment. CD $8^{+}$lymphocytes, as well as IL- 6 and TGF- $\beta 1$, may play key roles in this process. Further research is needed to determine the regulatory mechanism by which PD-1 inhibitors aggravate the immune microenvironment of RILI, as it may provide clues to the prevention and treatment of lung injury caused by radiation combined with PD-1 inhibitors.

\section{Acknowledgments}

This work was supported by grants from the Guizhou Provincial Natural Science Foundation, China [Grant number [2020]1Y338]; National Natural Science Foundation of China [Grant number 81960548]; and the Talent innovation and venture project of Lanzhou city [Grant number 2021-RC-125].

\section{Author Contributions}

All authors made a significant contribution to the work reported, including in conception, study design, execution, acquisition of data, and/or analysis and interpretation. All authors took part in drafting, revising and/or critically reviewing this submission; and all provided final approval of the version to be published; have agreed on the journal to which the article has been submitted; and agree to be accountable for all aspects of the work.

\section{Disclosure}

The authors report no conflicts of interest in relation to this work.

\section{References}

1. Siegel RL, Miller KD, Fuchs HE, Jemal A. Cancer statistics, 2021. CA Cancer J Clin. 2021;71(1):7-33. doi:10.3322/caac.21654

2. Doi T, Piha-Paul SA, Jalal SI, et al. Safety and antitumor activity of the anti-programmed death-1 antibody pembrolizumab in patients with advanced esophageal cCarcinoma. J Clin Oncol. 2018;36(1):61-67. doi:10.1200/JCO.2017.74.9846

3. Reck M, Rodriguez-Abreu D, Robinson AG, et al. Five-year outcomes with pembrolizumab versus chemotherapy for metastatic non-small-cell lung cancer with PD-L1 tumor proportion score $\geq$ 50. J Clin Oncol. 2021;39(21):2339-2349. doi:10.1200/JCO.21.00174

4. Ribas A, Wolchok JD. Cancer immunotherapy using checkpoint blockade. Science. 2018;359(6382):1350-1355. doi:10.1126/science.aar4060

5. Demaria S, Coleman CN, Formenti SC. Radiotherapy: changing the game in immunotherapy. Trends Cancer. 2016;2(6):286-294. doi:10.1016/j. trecan.2016.05.002

6. Wirsdorfer F, Cappuccini F, Niazman M, et al. Thorax irradiation triggers a local and systemic accumulation of immunosuppressive CD4+ FoxP3+ regulatory T cells. Radiat Oncol. 2014;9(1):98. doi:10.1186/1748-717X-9-98 
7. Ying HJ, Fang M, Chen M. Progress in the mechanism of radiation-induced lung injury. Chin Med J. 2020;134(2):161-163. doi:10.1097/ CM9.0000000000001032

8. Suresh K, Naidoo J, Lin CT, Danoff S. Immune checkpoint immunotherapy for non-small cell lung cancer: benefits and pulmonary toxicities. Chest. 2018;154(6):1416-1423. doi:10.1016/j.chest.2018.08.1048

9. Suresh K, Voong KR, Shankar B, et al. Pneumonitis in non-small cell lung cancer patients receiving immune checkpoint immunotherapy: incidence and risk factors. $J$ Thorac Oncol. 2018;13(12):1930-1939. doi:10.1016/j.jtho.2018.08.2035

10. Antonia SJ, Villegas A, Daniel D, et al.; PACIFIC Investigators. Overall survival with durvalumab after chemoradiotherapy in stage III NSCLC. $N$ Engl J Med. 2018;379(24):2342-2350. doi:10.1056/NEJMoa1809697

11. Durm GA, Jabbour SK, Althouse SK, et al. A Phase 2 trial of consolidation pembrolizumab following concurrent chemoradiation for patients with unresectable stage III non-small cell lung cancer: Hoosier Cancer Research Network LUN 14-179. Cancer. 2020;126(19):4353-4361. doi:10.1002/ cncr.33083

12. Peters S, Felip E, Dafni U, et al. Safety evaluation of nivolumab added concurrently to radiotherapy in a standard first line chemo-radiotherapy regimen in stage III non-small cell lung cancer-The ETOP NICOLAS trial. Lung Cancer. 2019;133:83-87. doi:10.1016/j.lungcan.2019.05.001

13. Voong KR, Hazell SZ, Fu W, et al. Relationship between prior radiotherapy and checkpoint-inhibitor pneumonitis in patients with advanced nonsmall-cell lung cancer. Clin Lung Cancer. 2019;20(4):e470-e479. doi:10.1016/j.cllc.2019.02.018

14. Nichols D, Boyle TA, Noyes D, et al. Evaluation of combined anti-PD-1 immunotherapy and radiation therapy in a preclinical mouse model of pneumonitis and fibrosis. J Thorac Dis. 2018;10(11):6254-6260. doi:10.21037/jtd.2018.10.01

15. Wang F, Luo Y, Tian X, et al. Impact of radiotherapy concurrent with anti-PD-1 therapy on the lung tissue of tumor-bearing mice. Radiat Res. 2019;191(3):271-277. doi:10.1667/RR15182.1

16. Jackson IL, Xu PT, Nguyen G, et al. Characterization of the dose response relationship for lung injury following acute radiation exposure in three well-established murine strains: developing an interspecies bridge to link animal models with human lung. Health Phys. 2014;106(1):48-55. doi:10.1097/HP.0b013e3182a32ccf

17. Matej R, Housa D, Pouckova P, Zadinova M, Olejar T. Radiation-induced production of PAR-1 and TGF-beta $1 \mathrm{mRNA}$ in lung of C57B16 and C3H murine strains and influence of pharmacoprophylaxis by ACE inhibitors. Pathol Res Pract. 2007;203(2):107-114. doi:10.1016/j.prp.2006.10.006

18. Downing L, Sawarynski KE, Li J, McGonagle M, Sims MD, Marples B. A simple quantitative method for assessing pulmonary damage after $x$ irradiation. Radiat Res. 2010;173(4):536-544. doi:10.1667/RR1712.1

19. Hanania AN, Mainwaring W, Ghebre YT, Hanania NA, Ludwig M. Radiation-induced lung injury: assessment and management. Chest. $2019 ; 156$ (1):150-162. doi:10.1016/j.chest.2019.03.033

20. Mrass P, Oruganti SR, Fricke GM, et al. ROCK regulates the intermittent mode of interstitial T cell migration in inflamed lungs. Nat Commun. 2017;8(1):1010. doi:10.1038/s41467-017-01032-2

21. Du S, Zhou L, Alexander GS, et al. PD-1 modulates radiation-induced cardiac toxicity through cytotoxic T lymphocytes. J Thorac Oncol. 2018;13 (4):510-520. doi:10.1016/j.jtho.2017.12.002

22. Lee Y, Auh SL, Wang Y, et al. Therapeutic effects of ablative radiation on local tumor require CD8+ T cells: changing strategies for cancer treatment. Blood. 2009;114(3):589-595. doi:10.1182/blood-2009-02-206870

23. Lai JZ, Zhu YY, Ruan M, Chen L, Zhang QY. Local irradiation sensitized tumors to adoptive T cell therapy via enhancing the cross-priming, homing, and cytotoxicity of antigen-specific CD8 T cells. Front Immunol. 2019;10:2857. doi:10.3389/fimmu.2019.02857

24. Chen Y, Hyrien O, Williams J, Okunieff P, Smudzin T, Rubin P. Interleukin (IL)-1A and IL-6: applications to the predictive diagnostic testing of radiation pneumonitis. Int $J$ Radiat Oncol Biol Phys. 2005;62(1):260-266. doi:10.1016/j.ijrobp.2005.01.041

25. Tabata C, Kubo H, Tabata R, et al. All-trans retinoic acid modulates radiation-induced proliferation of lung fibroblasts via IL-6/IL-6R system. Am $J$ Physiol Lung Cell Mol Physiol. 2006;290(3):L597-L606. doi:10.1152/ajplung.00282.2005

26. Fishman JA, Hogan JI, Maus MV. Inflammatory and infectious syndromes associated with cancer immunotherapies. Clin Infect Dis. 2019;69 (6):909-920. doi:10.1093/cid/ciy1025

27. Saito A, Horie M, Nagase T. TGF- $\beta$ signaling in lung health and disease. Int J Mol Sci. 2018;19(8):2460. doi:10.3390/ijms19082460

28. Wang S, Campbell J, Stenmark MH, et al. Plasma levels of IL-8 and TGF- $\beta 1$ predict radiation-induced lung toxicity in non-small cell lung cancer: a validation study. Int J Radiat Oncol Biol Phys. 2017;98(3):615-621. doi:10.1016/j.ijrobp.2017.03.011

29. Alam A, Mukhopadhyay ND, Ning Y, et al. A preliminary study on racial differences in HMOX1, NFE2L2, and TGF $\beta 1$ gene polymorphisms and radiation-induced late normal tissue toxicity. Int J Radiat Oncol Biol Phys. 2015;93(2):436-443. doi:10.1016/j.ijrobp.2015.05.049

30. Stenmark MH, Cai XW, Shedden K, et al. Combining physical and biologic parameters to predict radiation-induced lung toxicity in patients with non-small-cell lung cancer treated with definitive radiation therapy. Int J Radiat Oncol Biol Phys. 2012;84(2):e217-e222. doi:10.1016/j. ijrobp.2012.03.067

31. Barcellos-Hoff MH, Dix TA. Redox-mediated activation of latent transforming growth factor-beta 1. Mol Endocrinol. 1996;10(9):1077-1083. doi:10.1210/mend.10.9.8885242

32. Judge JL, Owens KM, Pollock SJ, et al. Ionizing radiation induces myofibroblast differentiation via lactate dehydrogenase. Am J Physiol Lung Cell Mol Physiol. 2015;309(8):L879-L887. doi:10.1152/ajplung.00153.2015

33. Rube CE, Uthe D, Schmid KW, et al. Dose-dependent induction of transforming growth factor beta (TGF-beta) in the lung tissue of fibrosis-prone mice after thoracic irradiation. Int J Radiat Oncol Biol Phys. 2000;47(4):1033-1042. doi:10.1016/S0360-3016(00)00482-X

34. Yang X, Ni J, Li Y, et al. LncRNA-RP11 modulates TGF- $\beta 1$-activated radiation-induced lung injury through downregulating microRNA-29a. Dose Response. 2020;18(4):1559325820949071. doi:10.1177/1559325820949071

35. Heukels P, Moor CC, von der Thusen JH, Wijsenbeek MS, Kool M. Inflammation and immunity in IPF pathogenesis and treatment. Respir Med. 2019;147:79-91. doi:10.1016/j.rmed.2018.12.015

36. Conte E, Gili E, Fagone E, Fruciano M, Iemmolo M, Vancheri C. Effect of pirfenidone on proliferation, TGF- $\beta$-induced myofibroblast differentiation and fibrogenic activity of primary human lung fibroblasts. Eur J Pharm Sci. 2014;58:13-19. doi:10.1016/j.ejps.2014.02.014

37. Ying H, Fang M, Hang QQ, Chen Y, Qian X, Chen M. Pirfenidone modulates macrophage polarization and ameliorates radiation-induced lung fibrosis by inhibiting the TGF- $\beta 1 /$ Smad3 pathway. J Cell Mol Med. 2021;25(18):8662-8675. doi:10.1111/jcmm.16821

38. Flechsig P, Dadrich M, Bickelhaupt S, et al. LY2109761 attenuates radiation-induced pulmonary murine fibrosis via reversal of TGF- $\beta$ and BMPassociated proinflammatory and proangiogenic signals. Clin Cancer Res. 2012;18(13):3616-3627. doi:10.1158/1078-0432.CCR-11-2855 
39. Vanpouille-Box C, Diamond JM, Pilones KA, et al. TGF $\beta$ is a master regulator of radiation therapy-induced antitumor immunity. Cancer Res. 2015;75(11):2232-2242. doi:10.1158/0008-5472.CAN-14-3511

40. Derynck R, Turley SJ, Akhurst RJ. TGFß biology in cancer progression and immunotherapy. Nat Rev Clin Oncol. 2021;18(1):9-34. doi:10.1038/ s41571-020-0403-1

\section{Publish your work in this journal}

The Journal of Inflammation Research is an international, peer-reviewed open-access journal that welcomes laboratory and clinical findings on the molecular basis, cell biology and pharmacology of inflammation including original research, reviews, symposium reports, hypothesis formation and commentaries on: acute/chronic inflammation; mediators of inflammation; cellular processes; molecular mechanisms; pharmacology and novel anti-inflammatory drugs; clinical conditions involving inflammation. The manuscript management system is completely online and includes a very quick and fair peer-review system. Visit http://www.dovepress.com/testimonials.php to read real quotes from published authors.

Submit your manuscript here: https://www.dovepress.com/journal-of-inflammation-research-journal 